\title{
CORRECTION
}

\section{Correction: Chronic maternal interleukin-17 and autism- related cortical gene expression, neurobiology, and behavior}

Serena Banu Gumusoglu, Benjamin Wen Qing Hing, Akanksha Sri Satya Chilukuri, Jessica Jolynn Dewitt, Sabrina Marie Scroggins and Hanna Elizabeth Stevens iD

Neuropsychopharmacology (2020) 45:1588; https://doi.org/10.1038/s41386-020-0701-4

Correction to: Neuropsychopharmacology https://doi.org/10.1038/ s41386-020-0640-0, published online 19 February 2020
This Article has been updated to add the following Supplementary files: Supplementary Tables 1, 2, 3, and 4. 